\title{
Akademietagung der AOTrauma Deutschland
}

Hans-Jörg Oestern, Thomas Mückley

Am 10. und 11. Mai 2018 fand in Erfurt die 2. Tagung der Akademie der AOTD mit 69 Mitgliedern statt.

Die Tagung lebte von einem regen Erfahrungsaustausch zwischen allen Teilnehmerinnen und Teilnehmern in einer lockeren Atmosphäre. Diskutiert wurden klinische Fälle unter dem Motto: „Der komplizierte Fall: aus Schwierigkeiten lernen" und die Themen Verzahnung ambulante/ stationäre Behandlung sowie Mitarbeitermanagement.

Die folgenden 15 Personen wurden neu in die Akademie aufgenommen: Bahrs (Tübingen), Hartensuer (Münster),
Huber-Wagner (München), Jungbluth (Düsseldorf), Kammerlander (München), Kösters (Greven), Kühne (Hamburg Wandsbek), Kunath (Erfurt), Märdian (Berlin), Özokyay (Wesel), Ruecker (Rendsburg), Sehmisch (Göttingen), Stein (Siegburg), Wutzler (Wiesbaden) und Zeckey (München). Damit hat die Akademie aktuell insgesamt 397 Mitglieder.

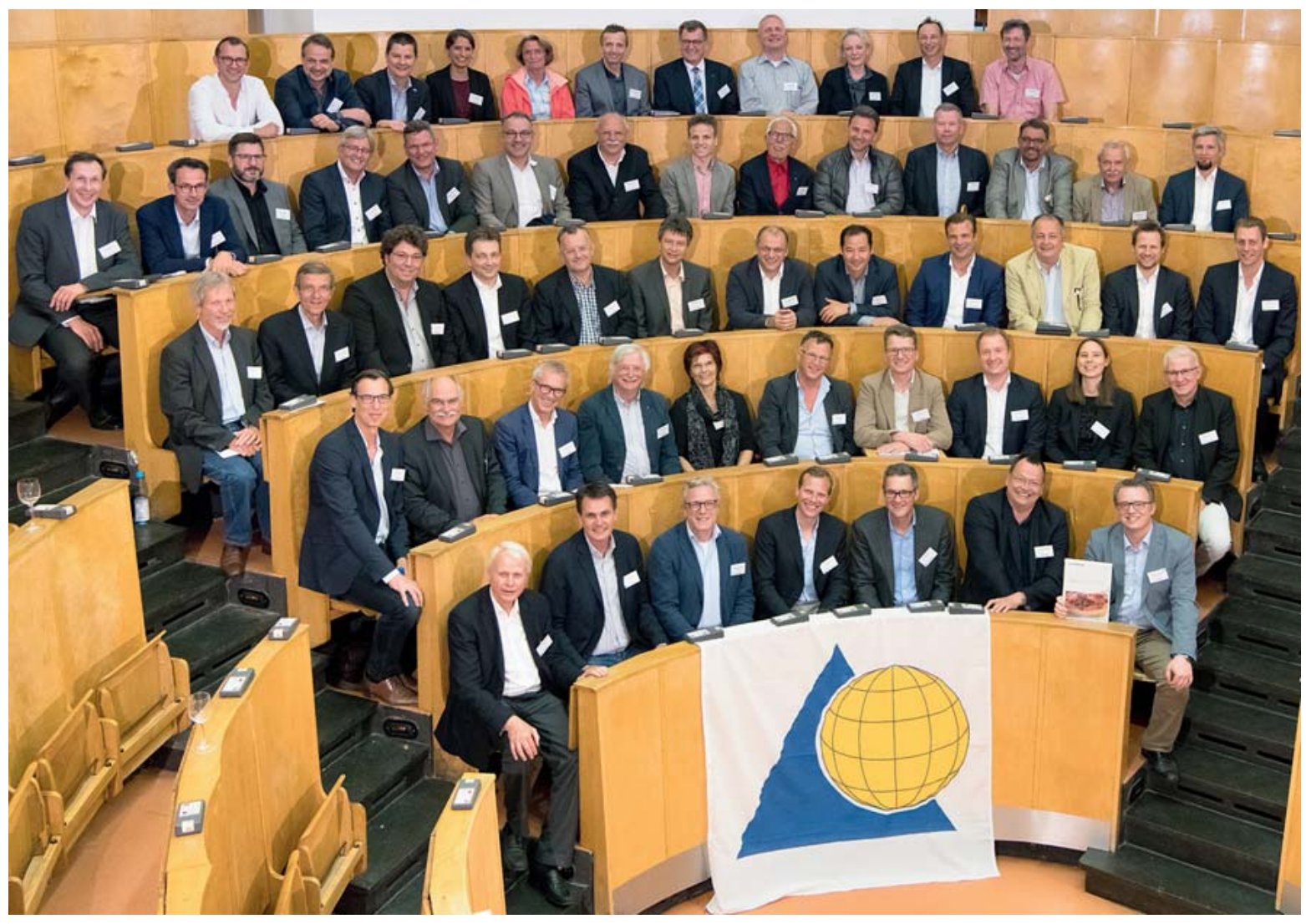

- Abb. 1 Teilnehmer der Tagung. Quelle: AO Foundation 


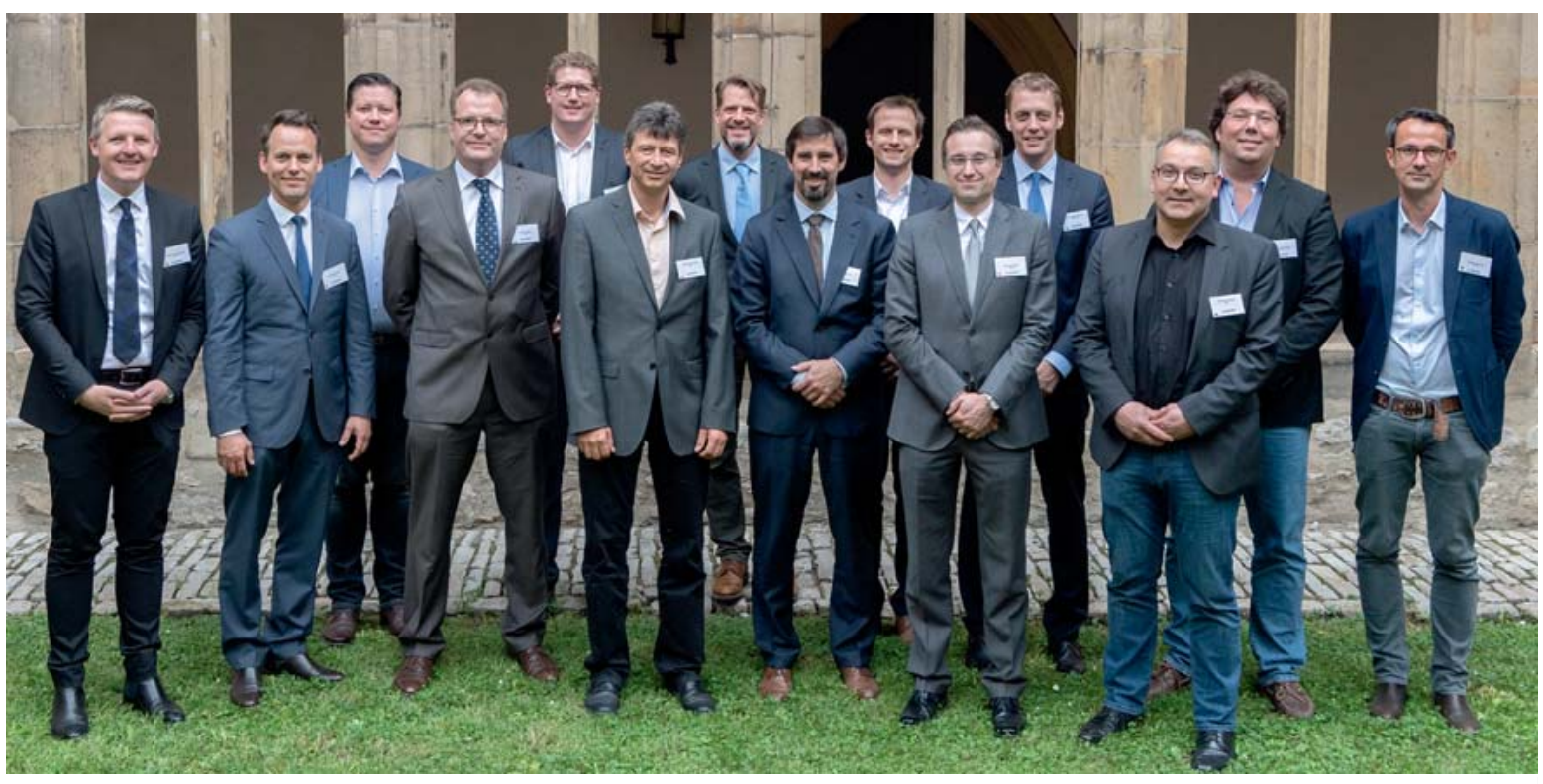

- Abb. 2 Neu aufgenommene Mitglieder der Akademie. Quelle: AO Foundation

Im Jahr 2019 findet wegen des 3-Länder-Treffens mit der AOT Österreich und Schweiz keine Tagung der Akademie statt. Die nächste ist deshalb erst wieder am 7. und 8. Mai 2020 in Mainz.

Prof. Dr. Hans-Jörg Oestern, Celle Prof. Dr. Thomas Mückley, Erfurt

\section{Bibliografie}

DOI https://doi.org/10.1055/a-0749-4559

OP-JOURNAL 2018; 34: 338-339 @ Georg Thieme Verlag KG Stuttgart · New York ISSN 0178-1715

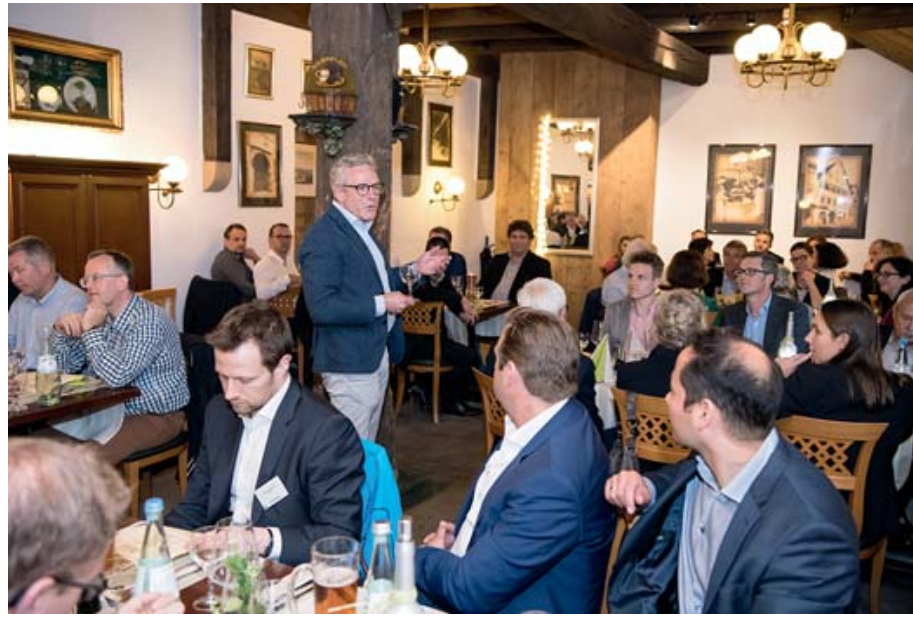

- Abb. 3 Ansprache von Präsident Raschke beim Abendessen. Quelle: AO Foundation 